\title{
Balancing personal and professional, faith and work, ideal and reality: A response to Paul Mariani
}

\author{
Thomas G. Plante
}

After reading Paul's paper, four words came to my mind over and over. (Four is a good theological number, I might mention.) It's a lovely paper, it's a thoughtful paper, it's a highly personal paper, and it's an honest paper. And so a lovely, thoughtful, highly personal, and honest paper, in my view, is so Catholic. And it's so Catholic because it highlights what Marc Muskavitch mentioned in our earlier conversation: "R and D." No, that is not "research and development," but rather reflection and discernment, which is what we're constantly doing in Catholic higher education.

It also underscores wrestling. As you can tell from Paul's presentation, he is wrestling. He is sweating. I don't know how he could wear a sweater when he gave that presentation. As I tell my own students, you have to wrestle with the topic. I teach an ethics class, for example, and I say if you're not wrestling with ethics, you're not trying. If you're not sweating, you're not trying. You must sweat.

This constant reflection, discernment, wrestling, ultimately leads to transformation. That transformational education is what we do: not only transformation in our students, but also transformation in us. Paul talks about that transformation and his own discernment process: he labored in the secular University of Massachusetts before he discerned a desire to come to the Jesuit-run Boston College at the age of sixty.

Paul began his paper with five frames: charism, host, guest, literary imagination, and intellectual hospitality. Paul defines charism as the special gift by the spirit for the good of

Thomas G. Plante is the Augustin Cardinal Bea, S.J. University Professor at Santa Clara University and adjunct clinical professor of psychiatry and behavioral sciences at Stanford University School of Medicine. He has served as the Psychology Department chair; acting dean of the School of Education, Counseling Psychology, and Pastoral Ministries; and director of the Spirituality and Health Institute at Santa Clara University. He recently served as vice-chair of the National Review Board for the Protection of Children and Youth for the U.S. Conference of Catholic Bishops and is the former president of the Society for the Psychology of Religion and Spirituality (Division 36) of the American Psychological Association. 
others. Do we understand how radical that is, and how radical that is today? We live in a radically narcissistic world, in a narcissistic culture. David Brooks recently observed the results of a survey of college students, answering the question, "Are you a very important person?" He noted that only fifteen percent of students in the I950s responded positively, compared with eighty percent today. ${ }^{\mathrm{I}}$ We live in a culture where every thought and every experience is shared on Facebook, Tweeted, and Instagrammed. And so a "charism that is a special gift by the spirit for the good of others" is a foil to narcissism, and that's something that we have in Catholic higher education that not everyone has.

Paul then goes on to talk briefly about host and guest and then the literary imagination. And all of this ultimately leads to this notion of value-added education. At Santa Clara, we talk about the three C's: competence, conscience, and compassion. And this is very much a part of our Jesuit higher education, of value-added education, ultimately addressing the whole person. And the whole person, as I've come to understand from my engagement with the medical, psychiatric, and psychological worlds, involves the entire bio-psycho-social-spiritual environment.

I've mentioned that Paul isn't afraid to wrestle. He is also not afraid to use the word "love." He's not afraid to see God in all things. And it's curious, and there is a sadness to it, that Paul mentions some of his own disappointments in Jesuit higher education, in terms of what courses are or are not offered in his department, how he looks to some other schools-he mentions Georgetown - that he felt were doing a little bit better job in the courses that are offered. More work is needed; we need to move the ball forward; the game is not over. But the fact that Paul offers some of his personal reflections and some of his personal disappointment underscores the notion that he cares and it matters and we want to do better. And so that's another very, I think, important part of Catholic higher education.

The images that Paul offered remind me of the famous words that Ignatius said to Francis Xavier, as Xavier left for Asia: "Go set the world on fire!" And I think that's what we're aiming for in Catholic higher education: to set the world on fire. Not just among the faculty, but among the students, among the staff, among all of us. And setting the world on fire means a certain degree of radical hospitality, radical love, radical transformation, and that it's always ongoing. Until the second coming, it's always ongoing.

And so this leads me to four questions. First: How do we balance the personal and the professional? How do we balance our story, what matters to us, our personal transformation? Paul so deeply, honestly shares his story. How do we balance that with the professional? What we are being paid to do, what we are being asked to do, what we are being expected to do? As a psychologist, I have always been trained that you don't say anything about yourself. I have patients whom I've seen for twenty-five years that know nothing about me other than when I'm working. When they ask me questions about myself, I always reflect it back to them and say: "Why is that important to you, what is

1. David Brooks, "The Modesty Manifesto," The New York Times, March 10, 2011, p. A27 (New York edition) your fantasy about that?" And so, this balancing of personal and professional—how do we do that? Paul's beautiful paper really highlights that issue.

Second: How do we balance faith and work? Even if we are enthusiastic Catholics, daily Mass kind of Catholics, card-carrying Catholics, how do we balance that with our work? Our faith with our somewhat secular jobs, how do we do that? Paul, again, wrestles with that in his paper. How honest are we? Do we turn our classes into group therapy and faith sharing groups? No. Where is that balance?

The third question also is about balance. How do we balance the now with the eternal? Paul talks about some of his experiences at the University of Massachusetts during the I970s, and the change in the core curriculum. In the academy, we are always wrestling with the now versus something that's more long-lasting. Are today's transformational activities sustainable? In higher education right now, there's a lot of attention toward online education. Everything is online. Do we all become the University of Phoenix or not? So this tension between now and eternal is a balancing question.

The last question is the balance between the ideal and the reality. We can be very aspirational, and I think Paul speaks to those aspirations, but we can also be very dis appointed by the reality. Paul articulates some of his disappointments in the reality of academic life. How do we balance our disappointment, our lack of support, lack of resources, money, and so forth, with the ideal?

In sum: How do we balance personal versus professional, our faith and the work, now versus eternal, and ideal versus reality? At the end of the day, how do we best set the world on fire, as Ignatius asked Francis Xavier? 